\title{
O seminário, escola dos pobres, em Manhã submersa (1953), de Vergílio Ferreira*
}

Graça dos Santos

Equipe d'accueil doctorale 369 "Etudes romanes", Université Paris Ouest Nanterre La Défensee. ***

E-mail: dos-santos.graca@wanadoo.fr

Resumo: No momento em que Salazar toma o poder como presidente do conselho (1932), o Seminário de Viseu já era uma solução de sobrevivência e de escolarização para os jovens garotos saídos de meios pobres; por sinal, o próprio chefe do Estado Novo o tinha experimentado, assim como Vergílio Ferreira, autor do romance Manhã submersa (Matin Perdu), que obteve o Prix Fémina 1990 na França. Ele narra o destino de António dos Santos Lopes, apelidado Borralho, que não teve outra escolha para se educar, senão esse mesmo seminário. Nós veremos em qual medida a ficção e a história desse jovem garoto, bem como as diversas etapas de seu destino, fazem eco na realidade de Portugal da época. Nós abordaremos a questão da escola e da religião e, por consequência, da laicização durante o Estado Novo de Salazar.

Palavras-chave: salazarismo, escola, religião, ficção, política.
Abstract: At the time in which Salazar takes over as prime minister (1932), the Seminary of Viseu was already a solution for the survival and education for young kids emerging from poor backgrounds and which, incidentally, the head of the Portuguese Estado Novo had experienced as well as the author of the novel, Vergílio Ferreira. Manhã submersa (Matin Perdu), which won the 1990 Prix Femina in France, narrates the fate of Antonio Lopes dos Santos, nicknamed Borralho, who had no other choice to be educated. We will see in which extent the fiction and the story of this young boy, as well as the various stages of his fate, echo in the Portuguese reality of the time. We will discuss the issue of school and religion and, therefore, the secularization along the Salazar's Estado Novo.

Keywords: salazarism, school, religion, fiction, politics.

Manhã submersa narra o destino de António dos Santos, apelidado Borralho, obrigado a entrar no Seminário de Viseu para fugir da miséria e para obedecer a D. Estefânia, beata rica que escolhera o garoto de 12 anos como distração para sua vida árida. O romance, situado na região pobre da Serra da Estrela, no Norte de Portugal, mostra a entrada do jovem garoto no seminário e sua permanência ali por quase quatro anos, assim como as férias que

Recebido: 08.12 .2008 Aprovado: 27.03.2009

* Tradução de Cristine Vargas Pereira e revisão técnica de Roseli Fígaro.

** CRILUS (Centre de Recherches Interdisciplinaires sur le Brésil et le Monde Lusophone). 
comunicação \& educação • Ano XIV • Número 3 • set/dez 2009

vão interromper essa estadia; tal período torna-se um verdadeiro pesadelo, do qual procura escapar. Mas ele não pode sair ileso dessa prova, que mutilará seu corpo e assombrará seu espírito.

\section{ENTRE ENUNCIAÇÕES MÚLTIPLAS E CONFUSÃO VOLUNTÁRIA}

Escrito em 1953, Manhã submersa é um romance que podemos qualificar como autobiográfico, sentimento visivelmente desejado pelo autor que opta por uma superposição do narrador (eu) com o personagem (António), mas também com o autor que experimentou o internato no seminário, apresentado como um universo verdadeiramente concentracionário.

Essa forma de confusão voluntária é revelada fora do próprio romance: durante entrevistas ${ }^{1}$, Vergílio Ferreira evoca retomadas vezes a experiência do seminário quando tinha apenas dez anos, seus pesadelos sobre esse tema e a interrupção deles após a escrita do romance; como António, ele tornou-se prematuramente órfão, e a falta do pai provocou-lhe problemas psíquicos (em face da pobreza afrontada pela mãe, única dirigente do lar) e morais (estando o lugar do pai vago, outros serão usurpadores dessa função fundamental para um jovem adolescente).

Essa problemática é manifestada na adaptação cinematográfica do romance, realizada por Lauro António nos anos 1980, em que o próprio Vergílio Ferreira interpreta o personagem do reitor do seminário, figura dominante desse universo fechado com o qual o autor ator parece acertar contas e por meio do qual exorciza essa prova dolorosa. Isso resulta numa forma de enunciação binária (narrador/personagem), indiretamente ternária (confusão induzida do narrador com o autor), e numa polifonia do discurso paradoxalmente centrípeto e centrado sobre o eu (principal enunciador); um tipo de fluxo de consciência final que narra e trata o vivido e experimentado em três ondas sucessivas.

Esse procedimento confere ao discurso a verossimilhança do vivido, mas opacifica os contornos. O ato da narração é lançado por António dos Santos Lopes em 1953, vinte anos após os acontecimentos (portanto, a ação se situaria nos anos 1930), e nessa ocasião almeja apenas narrá-los. Trata-se então de um mundo reconstruído de memória ao qual se acrescenta um outro criado pelo ato da escrita. Como separar o eu que vive a história do mundo exterior e extirpar

1. ANTÓNIO, Lauro. Manhã submersa. Do romance de Vergílio Ferreira, apresentação do filme de Lauro António por ele mesmo. Texto datilografado.

2. GOULART, Rosa Maria. Romance lírico: o percurso de Vergílio Ferreira. Venda Nova: Bertrand Editora, 1990. p. 43. de um e de outro o discurso propriamente dito? ${ }^{2}$ Esse funcionamento alarga o horizonte do texto, não o reduzindo a um universo anedótico e trabalhando com facilidade a metáfora.

A história de Manhã submersa se constrói segundo a relação entre dois mundos que tentam se sobrepor: de um lado a sociedade e a instituição e, de outro, o mundo individual do personagem e sua própria interioridade. Ambos são fontes de mazela: na casa maternal o protagonista não acha mais seu lugar, pois ele fica dividido entre sua família e a casa de Dona Estefânia; o seminário o subjuga, supervisiona sua personalidade e condiciona seu comportamento. 
O seminário, escola dos pobres, em Manhã submersa • Graça dos Santos

É a luta desigual que se trava entre o personagem e o espaço, e onde o indivíduo é oprimido em face do(s) sistema(s) (tanto o sistema do mundo social, que ele aceita e onde é o mais baixo na escala, quanto o sistema do seminário, aparelho laminador de corpos e espíritos que evoca o dispositivo implantado por Salazar para condicionar a população portuguesa).

A metáfora permite então analogias entre o universo conhecido do personagem e o ignorado por ele, entre o que lhe é próximo e o que lhe é distante, entre o que lhe é imposto e o que ele desejaria. Esse emprego repetido da metáfora, em sua forma hiperbólica e ligado à personificação gigantesca, à metonímia e à sinédoque, constrói o ponto de vista do adolescente diante da iniciação em um mundo que ele desconhece e quer assimilar. Nesse sentido, a descrição da chegada ao seminário é particularmente emblemática:

Lentamente, o casarão foi rodando com a curva da estrada, espiando-nos do alto da sua quietude lôbrega pelos cem olhos das janelas. Até que, chegados à larga boca do portão, nos tragou a todos imediatamente, cerrando as mandíbulas logo atrás ${ }^{3}$.

O gigantismo e a monstruosidade do edifício figuram também o horror previsível do sistema de opressão que ele mantinha e que evoca a situação ditatorial de Portugal da época. A passagem de uma língua a outra atenua o efeito produzido pelo texto português: o seminário, qualificado em francês de grand bâtisse, era casarão, aumentativo português de casa, que, associado à descrição monstruosa do edifício, personificado e colocado em movimento, evoca o papão, o ogro dos contos para crianças.

A chegada noturna das jovens crianças, já pressentidas como vítimas potenciais, nos transporta para o universo da ficção das fábulas infantis, mas os procedimentos escolhidos pelo autor, evocados anteriormente (a confusão entre o narrador e o personagem principal, o caráter quase autobiográfico da narrativa), nos indicam a superposição com a realidade da época: não se trata apenas de uma história a ser lida para as crianças, que se sentem atraídas por um medo que elas sabem ser de origem fictícia. Trata-se de um procedimento metafórico que permite sugerir uma crítica da situação real vivida pelos portugueses de então, e que a censura salazarista não teria admitido se ela tivesse sido claramente formulada. Nesse sentido, o ogro não seria Salazar e esses jovens garotos, os próprios portugueses infantilizados pelo Estado Novo?

\section{SALAZARISMO E SEMINÁRIO: UMA METÁFORA USUAL}

Do começo ao fim, o romance induz a essa metáfora global com o salazarismo. Convém, no entanto, antes de nos debruçarmos em associações comparativas, lembrar que o próprio Salazar fequentou o seminário. Um dos capítulos de Vacances avec Salazar (Férias com Salazar), de Christine Garnier - título a ser incluído na lista de obras salazaristas para glória do ditador português, publicadas na França -, intitulado O seminarista de Viseu, é seguido por uma entrevista
3. FERREIRA, Vergílio. Matin perdu (Manhã submersa). Traduction française de Parcidio Gonçalves. Paris: Editions de la Différence, 1990. p. 21. Obra original: FERREIRA, Vergílio. Manhã submersa. Amadora: Bertrand, 1980. p. 21. 
comunicação \& educação • Ano XIV • Número 3 • set/dez 2009

entre a jornalista francesa e Mário de Figueiredo, que tinha sido condiscípulo de Salazar no Seminário de Viseu e mais tarde se tornou seu ministro da Educação.

Ressaltamos de maneira sintomática que tal ministro foi escolhido para falar da educação de Salazar, como maneira de introduzir furtivamente a ideia de um modelo comportamental para imprimir aos jovens portugueses ${ }^{4}$.

- Salazar passou oito anos no seminário, não é? - Eu perguntava. - Isso aconteceu devido a uma ardente vocação religiosa?

- Eu não creio - responde Mário de Figueiredo. - Era habitual, na época, que as famílias numerosas destinassem um filho à Igreja. Esse costume favorecia os pais com salários mais modestos: o seminário concedia estudos gratuitos. Quando terminou seu curso, ninguém se surpreendeu com sua renúncia ao sacerdócio. Muitos de nossos camaradas não tinham feito o mesmo?

- Asseguram-me de que ele dissera: "Eu servirei melhor à Igreja e a Portugal no campo laico". Ele me parecia, entretanto, marcado por seus anos de seminário e ensino recebido em Viseu. Não é o ascetismo a regra de sua vida, e o serviço do Estado seu sacerdócio?

Mário de Figueiredo inclina a cabeça em sinal de assentimento [...].

- [...] você vê no Presidente do Conselho traços de caráter que lembram o Salazar do seminário?

- Eu creio poder dizer que Salazar, desde aqueles anos longínquos, não mudou: sua vida é uma linha reta - responde ele. - [...] A prudência que ele mostrava já no seminário, nós a achamos intensificada. [...] Há nele muito de sutileza e de pudor. Quando nos encontramos diante de Salazar, é preciso pressentir, sempre adivinhar, guardar para si as perguntas. [...] Parece-me que o vejo passar diante da igreja da Misericórdia, por meio dos padres furtivos com o olhar baixo, um Salazar adolescente vestido inteiramente de preto $^{5}$.

Assim, Salazar poderia ter sido um dos condiscípulos de António. Certamente não um daqueles que se revoltaram, como o herói de Manhã submersa, que se mutila para deixar o seminário. Não, sua única irreverência teria sido deixar o seminário sem se tornar padre, ato aqui justificado no texto de propaganda pelo fato de o mentor do Estado Novo conceber seu poder como um sacerdócio, por meio do qual serviria ainda melhor à Igreja e a Portugal no campo laico. E evoca o efeito benéfico do seminário sobre esse personagem, chefe exemplar: "Essa famosa disciplina dos atos, dos sentimentos, e até da voz, que não cessou de observar durante sua vida" ${ }^{\prime \prime}$.

Quando se trata de lembrar os lugares da vida de Salazar, fala-se em de Figueiredo, professor de Direito, foi ministro da Educação de 28/08/1940 a 06/09/1944

5. GARNIER, Christine. Vacances avec Salazar (Férias com Salazar). $\mathrm{Pa}$ ris: Grasset, 1952. p. 45.

6. Ibid., p. 44.

7. Ibid.

8. Ibid.

9. Ibid., p. 42. 
O seminário, escola dos pobres, em Manhã submersa • Graça dos Santos

\section{A RELIGIÃO CATÓLICA, ELEMENTO CONSTITUTIVO DE IDENTIDADE NACIONAL}

Ao voto de castidade de Salazar, colocado em destaque pela propaganda de seu regime, está associada a discrição, o apagamento, características evidentes da representação de seu poder e que tende a diferenciá-lo dos outros ditadores de sua época. A disciplina dos atos, relatada por Christine Garnier, é retomada pela ordem corporativista concebida pelo Estado Novo, cuja lógica está inteiramente contida na famosa máxima: "Um lugar para cada um e cada um em seu lugar"10, que subentende uma ordem orgânica natural a qual cada um deve se submeter e que pretende anular qualquer tipo de vontade de protagonismo, bem como, por fim, inculcar a obediência à ordem estabelecida pelo regime salazariano.

O passado de Salazar como seminarista liga de maneira indelével sua educação à Igreja, elemento claramente indicativo de um dos mitos do salazarismo, "o da essência católica da identidade nacional" famosa trilogia salazariana, Deus - Pátria - família, que supostamente institui os preceitos de seu Estado Novo. Gustavo Cordeiro Ramos, um de seus mais marcantes ministros da Educação, afirma em 1936:

Sob a máscara do laicismo, é feita uma obra criminosa, antissocial e antipatriótica de descristianização. A religião deve ser considerada como uma necessidade do Estado. [...] A ordem nova com seus conceitos dominantes, de autoridade e de nação, somente pode ser compreendida admitindo uma ordem superior. É inaceitável sem a ideia e a prática de Deus ${ }^{12}$.

E um de seus sucessores precisa ainda:

Uma coisa é a separação da Igreja e do Estado, que conserva a Constituição de 1933, e outra o espírito laico que é contrário à Constituição, à ordem social, à família e à própria natureza humana. Bem pior que as trevas do analfabetismo em um coração puro é a instrução materialista e pagã que asfixia as melhores inclinações ${ }^{13}$.

O espírito laico não deve então, de modo algum, figurar na escola concebida por Salazar e será de alguma maneira exorcizado pela presença repetida do crucifixo em seus edifícios. Determinadas escolas mantêm até hoje essa tradição do crucifixo afixado na parede. Tal fato ocasionou a guerra dos crucifixos, enquanto a campanha eleitoral em torno das eleições presidenciais era lançada em Portugal. Estas foram realizadas num domingo, 22 de janeiro de 2006, com a vitória de Aníbal Cavaco Silva, representante do partido de direita liberal (PSD), que declarou que a retirada dos crucifixos das escolas não era a ordem do dia.

Os propósitos dos ministros da educação do Estado Novo provam que o objetivo deles não se relaciona unicamente com a "elaboração de programas de construção de escolas, mas deve visar à orientação apropriada da vida individual e nacional. [...] O objetivo não era somente ensinar e educar politicamente no sentido nobre da palavra" ${ }^{14}$. Trata-se mais amplamente de "formar o homem novo" ${ }^{15}$. Carneiro Pacheco pediria aos professores para "ajudar os pais a mol-
10. Fórmula de António Faria Carneiro Pacheco, ministro da Educação de Salazar de 18/01/1936 a 09/03/1939, citado por ROSAS, Fernando. Le salazarisme e l'homme nouveau, essai sur l'homme nouveau et la question du totalitarisme dans les années trente et quarante (O salazarismo e o homem novo: ensaio sobre o homem novo e a questão do totalitarismo nos anos trinta e quarenta). In: BONUCCl, Marie-Anne Matard; MILZA, Pierre (Dir.). L'homme nouveau dans l'Europe faciste (1922-1945). Entre dictature et totalitarisme $(\mathrm{O}$ homem novo na Europa fascista [1922-1945]: entre a ditadura e o totalitarismo). Paris: Fayard, 2004. p. 92.

11. Ibid.

12. Gustavo Cordeiro Ramos, professor de Literatura, foi ministro da Educação por quatro vezes (de 10/11/1928 a 07/08/1929), e durante mais três mandatos (de 21/01/1930 a 23/07/1933). RAMOS, Gustavo Cordeiro. Os fundamentos éticos da escola no Estado Novo. Edição União nacional, 1937, citado por ROSAS, op. cit.

13. PACHECO, António Faria Carneiro. Na recepção ao pessoal do ensino primário. Escola portuguesa, n. 69, 136, p. 3, citado por ROSAS, op. cit.

14. ROSAS, op. cit., p. 100.

15. Ibid. 
comunicação \& educação • Ano XIV • Número 3 • set/dez 2009

dar o futuro homem português na cera sensível e plástica que é o cérebro da criança"16. Esta citação evoca a de Salazar sobre o tema de sua política que ele define como o caso do prego que fez uma pressão suave, mas constante, penetrando pouco a pouco, sem provocar a reação viva da matéria. Trata-se da educação do povo português em sua globalidade, que aqui é formulada como uma maneira de indução lenta, de persuasão ${ }^{17}$.

Esse mesmo ministro da Educação não crê totalmente na capacidade da estrutura familiar para o trabalho educativo; para ele falta competência, o que deve, por consequência, paliar o Estado. Em Manhã submersa, esse questionamento da conformidade da vida do aluno fora do meio escolar é agravado pela falta do pai, autoridade fundadora da família concebida por Salazar. É, pois, para seu bem que António é tirado de sua mãe, sem que ela manifeste resistência aparente. Qual melhor lugar do que o seminário para formar um homem à imagem de Salazar? Melhor ainda, formar um padre, futuro guia das almas em direção à Igreja e, na mesma tacada, em direção à submissão do Estado Novo. É, portanto, dessa maneira que é apresentado o padre da igreja do vilarejo, o qual António reencontra durante suas acidentais férias: ele e D. Estefânia são os fiadores do seminário e estão lá para impedir qualquer escorregão fora do claustro.

Todo contato direto é evitado entre António e sua mãe, e ela e seus irmãos são sempre denegridos por D. Estefânia.

Descobri então minha mãe, pesada, coberta de negro, e corri ansioso para ela, como para um refúgio de fim. Ela, porém, quase me não falou. $\mathrm{E}$, depois de me beijar brevemente, disse-me em voz surda e medrosa: - A senhora. Olha a senhora $^{18}$. Sem se mover, não ousando tocar-me, disse-me apenas "meu filho", e ficou a olhar-me em silêncio. Eu sentia sobre mim o suplício dos olhos de D. Estefânia, que um pouco atrás assistia ao encontro; $[\ldots]^{19}$.

16. Ibid., p. 101

17. Cf. FERRO, António. Salazar le Portugal et son chef (Salazar, Portugal e o seu chefe). Paris: Bernard Grasset, 1934. p. 247.

18. FERREIRA, Matin perdu, cit., p. 67.

19. Ibid., p. 73.

20. CARVALHO, Alberto Arons de. Da liberdade de imprensa, p. 410

\section{O MEDO, A OBSCURIDADE}

A imagem da negação da luz é frequentemente utilizada para expressar a ditadura salazarista evocada por vezes como um longo túnel, um período obscuro, que metaforiza uma forma de luto vivido pelos portugueses, mas igualmente a política de sigilo do regime que abafava, ao mesmo tempo, as potenciais dissidências e o vestígio de sua ação coerciva. Ferreira de Castro, em 30 de novembro de 1946, durante a sessão do Movimento da Unidade Democrática (MUD, movimento de oposição criado logo após a vitória de aliados), depois de vinte anos de ditadura, evoca um país onde falta a luz, onde tudo é feito $a$ portas fechadas e de forma lenta: "Não se fala, ou se cala, ou se murmura sob um tom de seminarista - alterando dessa maneira o natural do temperamento humano. Seria exagero afirmar que, durante os últimos vinte anos, nós vivemos em Portugal como em um grande seminário?”"20.

Da mesma maneira, Manhã submersa é caracterizada pela obscuridade quase perpétua, simbolizada pelo traje negro dos jovens seminaristas por vezes qualificados de corvos: 
O seminário, escola dos pobres, em Manhã submersa • Graça dos Santos

Aniquilados, tensos de expectativa, a sombra do Seminário chegava já até ali, pesava densamente sobre todos ${ }^{21}$. [...] Uma torrente negra de seminarista inundou tudo. Submerso na noite, perdido na confusão dos fatos pretos [...] eu suava de cansaço e de ansiedade ${ }^{22}$.

Os propósitos do personagem-narrador no momento de começar sua narrativa são absolutamente significativos:

Falo agora à memória destes últimos vinte anos e pergunto-me que destino atravessou a minha vida além desse pavor, que outra voz mensageira lhe clamou o futuro além da voz de uma noite sem fim²3.

As descrições consecutivas do seminário, do dormitório, do refeitório, ao longo de todo o romance, apontam incessantemente para a falta de luz e a imensidão dos lugares onde os corpos dos pensionistas se perdem e desaparecem. A essa obscuridade onipresente está associado o medo, porque os garotos, incessantemente vigiados pelos padres, ficavam aterrorizados.

O desafio dos meus olhos era o medo de todo meu corpo alerta, de um terror recurvo à escuta ${ }^{24}$. [...]. Mudos e quedos, ao pé dos muros, apareceram-me ainda, ao longo do corredor, vários padres de sentinela. E na pura ameaça do seu olhar de sombra, eu sentia, mais escura, a grandeza ilimitada de um pavor abstrato ${ }^{25}$.

Essa sensação de vigilância pesada, tal uma espada de Dâmocles, indica a metáfora do poder ditatorial e de sua polícia política que agia durante a noite, sem deixar traços:

Mas o que mais me aterrorizou foi aquela súbita presença invisível do Prefeito, vinda do fundo da noite, imensa, ilimitada, sem a materialização de um corpo, de um breve ruído de pés. Pelos anos afora, eu havia de encontrá-los, a esses medos, pelo escuro dos corredores, das escadarias, calados, imóveis, rondando-nos de sombra e de ameaça ${ }^{26}$.

\section{UM SISTEMA DE PERSUASÃO}

Os qualificativos para representar esse pavor abstrato e ilimitado pareciam sempre insuficientes; no momento em que ele invadia a personalidade, cercando-a por completo, era como se as palavras não pudessem descrevê-lo. Na realidade, é um sistema de persuasão descrito ao longo dos capítulos. A primeira aparição do reitor do seminário é emblemática da dominação progressiva dos seminaristas:

Entrou clandestinamente pela porta superior da Capela, rezou, pôs-se enfim de pé, em frente do altar-mor. Não era um homem alto, nem rude, nem agressivo. Tinha uma fala doce, vagarosa, levemente nasal. E, que eu saiba, nunca aplicou a nenhum aluno qualquer castigo violento. E, no entanto, à distância destes anos donde agora o estou lembrando, ele levanta-se ainda como o símbolo mais perfeito do terror. Porque a força que vinha dele, a espantosa dimensão do seu medo, não tinha cargas de sombras, muito menos suspeitas de tortura. Não era o medo de um bruxo nem de um carrasco. O terrorismo dele era puro silêncio ${ }^{27}$.

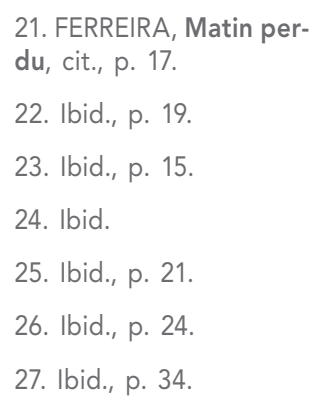


28. Nós evocamos de maneira mais detalhada as particularidades de Salazar e do salazarismo em SANTOS, Graça dos. Le spectacle dénatu ré le théâtre portugais sous le règne de Salazar (1933-1968) (O espetáculo desvirtuado: o teatro português sob o reinado de Salazar [1933-1968]). Paris: CNRS Editions, 2002

29. FERREIRA, Matin perdu, cit., p. 41.

30. Ibid., p. 41-42.

31. Ibid., p. 89-90.

32. Ibid., p. 23

33. Ibid., p. 29

34. Ibid., p. 33. comunicação \& educação • Ano XIV • Número 3 • set/dez 2009

Essa aparição evoca Salazar e as particularidades do salazarismo. Diferentemente de outros ditadores, Salazar era pouco inclinado às demonstrações públicas; reservado, não amava discursar para as multidões e lia seus discursos. Os portugueses eram mais habituados a sua voz que a sua presença física. Sua política não era feita de um terror ostentado, mas de dissimulação acalentada que produz um universo obscuro e calafetado. A força dessa forma de poder residia precisamente no segredo preservado, deixando à população, como única liberdade, imaginar os castigos que lhe seriam reservados se enfrentasse as regras impostas ${ }^{28}$. Trata-se, pois, de insinuar o medo, uma forma de indução que opera por sugestão, por cerceamento da personalidade, e impele o indivíduo à autocensura, deixando-o crer que é sujeito de suas ações.

António experimenta duas vezes essa maneira de escamotear inteiramente o livre arbítrio. Quando ele parece desenvolver uma forma de resistência ao sistema de persuasão e a dúvida começa a se insinuar, ele é convocado à sala do reitor.

Desencadeei então um ataque brutal a todo o meu corpo pequeno, cravei as unhas nas palmas das mãos, aguentei-me ${ }^{29}$.

Mas ele pôde apenas constatar:

Voltei da reitoria sucumbido, mas cheio de gratidão; porque, depois de me forçar a medir o meu crime, o reitor, afinal, não me castigara. Por isso, com um secreto orgulho de ter saído incólume daquele lance perigoso, acometeu-me subitamente o desejo de clamar, para a lonjura dos salóes, a bondade do reitor, a sua grandeza de Senhor ${ }^{30}$.

O ser é assim perfeitamente submisso, mas a manipulação é ainda mais realizada à medida que o sujeito a reconhece.

A dúvida que vem atormentar o jovem seminarista na clausura do seminário corresponde ao experimentado quando estava em férias na casa de Dona Estefânia. Após ter coagido o garoto a se contradizer, ela acena novamente:

- Bem, António. Espero que já tenhas refletido com Deus sobre aquilo que disseste. Parece-te que não tens vocação?

- Tenho, sim, minha senhora. [...]

- Bem, meu filho. Vai agradecer a Deus ter-te livrado da tentação. Vai e pede ao Senhor que te defenda sempre das ciladas do Demônio. [...]; "Levantei-me quase feliz"'31,

teve de admitir o garoto. Essa rendição não é apenas mental, é também física. Os jovens seminaristas são condicionados por preces incessantes das quais eles não podem escapar. Em face disso o corpo se rende:

Um toque de campainha dobrou-nos pelos joelhos. E foi assim, vencido, cortado pelo meio, que eu fiquei a recordar-me para minha vida inteira ${ }^{32}$. [...] E, às dez da noite, vencidos, sovados de alarme e de cansaço, metíamo-nos todos na cama. $[\ldots]^{33}$ pelo instinto da minha submissão milenária, ainda me soergui $[\ldots]^{34}$. 
O seminário, escola dos pobres, em Manhã submersa • Graça dos Santos

\section{A IMPRESSÃO INDELÉVEL}

É, entretanto, por meio de seu corpo, o qual quiseram curvar e ao mesmo tempo arrancar sua vontade, que o personagem-narrador quer se revoltar. Ato de uma violência extraordinária, o jovem adolescente escolhe a automutilação para deixar o inferno. Durante uma festa de aniversário na casa de Dona Estefânia, é a ele que pedem para soltar o fogo de artifício; ele, o filho do povo, deve se devotar e correr o risco de se machucar: "Sim. Portanto, minha carne podia arder" ${ }^{\prime 5}$, verifica António. Isto lhe inflige então um suplício extremo e provoca a explosão que vai amputar-lhe dois dedos. O ferimento indica ao mesmo tempo a força de caráter do personagem e também uma forma de fracasso físico: a mutilação figura ao mesmo tempo uma grande coragem, mas também a entrega à única escapatória que evoca a castração. É a constatação de um corpo ao qual recusaram toda forma de vida própria, enquanto a adolescência é ainda a idade dos primeiros apelos da carne. Esse gesto de desespero final lembra a autocensura do escritor português que, durante o Estado Novo, realizava a adaptação de sua narrativa a fim de não ver o texto proibido. É também uma metáfora dolorosa para indicar que não se pode sair ileso desse gênero de experiência, e que o traço físico de impressão do poder ficará conservado para sempre ${ }^{36}$.

Em sua vontade de formar o homem novo, Salazar concebe os seres como um material modelável que ele pretende fabricar por indução mediante um sistema de persuasão, verdadeiro molde dos corpos e das mentalidades. Formar é aqui sinônimo de educar e se entende de maneira global. A escola é um dos lugares privilegiados por se encarregar de crianças; integra a formação religiosa como fazendo parte do ensino. O único livro do programa inclui a prece e a catequese. Antigo seminarista, Salazar utiliza a Igreja para melhor apoiar seu poder. Manhã submersa, extraordinária metáfora do salazarismo, desvela as mais complexas engrenagens dessa forma de poder sofisticada: um Estado Novo "encarregado de fabricar pela força, sem alternativa, renegando os espaços privados ou de autonomia, um novo ser virtuoso que seria o suporte da defesa e da reprodução da ordem nova" ${ }^{37}$.

\section{REFERÊNCIAS BIBLIOGRÁFICAS}

ANTÓNIO, Lauro. Manhã submersa. Do romance de Vergílio Ferreira, apresentação do filme de Lauro António por ele mesmo. Texto datilografado.

CARVALHO, Alberto Arons de. Da liberdade de imprensa. Lisboa: Editora Meridiano Limitada, 1971.

FERREIRA, Vergílio. Matin perdu (Manhã submersa). Traduction française de Parcidio Gonçalves. Paris: Editions de la Différence, 1990.

. Manhã submersa. Amadora: Bertrand, 1980.

Manhã submersa. Lisboa: Círculo de leitores, 1975.

35. Ibid., p. 198

36. Desenvolve-se uma forma de dependência entre a vítima e seu torturador, entre a censura e seu censor. Sobre este tema, ver LEGENDRE, Pierre. L'amour du censeur (O amor do censor). Paris: Le Seuil, 1974.

37. ROSAS, op. cit., p. 107. 
comunicação \& educação • Ano XIV • Número 3 • set/dez 2009

FERRO, António. Salazar, le Portugal et son chef (Salazar, Portugal e seu chefe). Paris: Bernard Grasset, 1934.

GARNIER, Christine. Vacances avec Salazar (Férias com Salazar). Paris: Grasset, 1952.

GOULART, Rosa Maria. Romance lírico: o percurso de Vergílio Ferreira. Venda Nova: Bertrand Editora, 1990.

LEGENDRE, Pierre. L'amour du censeur (O amor do censor). Paris: Le Seuil, 1974.

REIS, João da Encarnação. A educação na literatura portuguesa. Lisboa: Edições Colibri, 2000.

ROSAS, Fernando. Le salazarisme e l'homme nouveau, essai sur l'homme nouveau et la question du totalitarisme dans les années trente et quarante (O salazarismo e o homem novo: ensaio sobre o homem novo e a questão do totalitarismo nos anos trinta e quarenta). In: BONUCCI, Marie-Anne Matard; MILZA, Pierre (Dir.). L'homme nouveau dans l'Europe faciste (1922-1945). Entre dictature et totalitarisme (O homem novo na Europa fascista (1922-1945): entre a ditadura e o totalitarismo). Paris: Fayard, 2004.

SANTOS, Graça dos. Le spectacle dénaturé le théâtre portugais sous le règne de Salazar (1933-1968) (O espetáculo desvirtuado: o teatro português sob o reinado de Salazar [1933-1968]). Paris: CNRS Editions, 2002. 